\title{
The Research on Power Grid Self-Healing in a High-Voltage Smart Grid
}

\author{
Guang-Liang YANG ${ }^{1, a,{ }^{*}, \text { Jing ZHOU }}{ }^{1, b}$, Yong WANG ${ }^{2, c}$ \\ ${ }^{1}$ State Grid International Development Company, Beijing, 100031, China \\ ${ }^{2}$ Henan Enpai Power Technology Company, Zhengzhou, 450016, China \\ a48098842@qq.com, bzhou.jing@stategrid.com.br, 'c45189247@qq.com \\ *Corresponding author
}

\begin{abstract}
Keywords: Smart Grid, Fault Identification, Video Technology, Self-Healing Grid, Tuning Control, Self-Prevention.
\end{abstract}

\begin{abstract}
In this paper, a concept of self-healing of high-voltage power grids and their research status are first introduced. Based on that, a new high-voltage power grid self-healing scheme is proposed. The collections of protective trip information, i.e. action set of each fault point, are initially utilized to establish an expert knowledge base in advance. When a fault happens, the action set will be formed according to the action information of breakers and protections gathered by a power grid control center. Then, it will be compared and contrasted with the action set in the expert knowledge base to determine the fault point. A $220 \mathrm{kV}$ smart grid control center in east China grid with a fault on its high-voltage power grid is taken as an example. The idea of high-voltage power grid self-healing is put forward, and the issues that need attention are summarized for prevention and tuning control during the self-healing process. The process of employing the expert knowledge base to identify the fault point, fault isolation and power grid restoration, are presented and then testified with the results from video technologies. The example shows that the proposed scheme can meet the requirement of self-healing for grids. It can isolate a fault automatically and quickly, and then restore the non-fault part. This proposed approach can fulfill as a good reference for the construction of smart grids at the moment.
\end{abstract}

\section{Introduction}

There are several power system blackouts happening world widely in recent years. Due to these incidents, power grid security has caught higher attention than ever before. To eliminate big blackouts, the United States, Western Europe and other countries have begun to build smart grids, which have the ability of self-prevention and auto-recovery. As well, State Grid Corporation of China has also released an agenda of building strong and smart grids. Self-healing ability is an important characteristic of smart grids [1-2] and meanwhile it is also part of the development and improvement of SCADA (supervisory control and data acquisition) system and EMS (energy management system).

Self-healing power control should keep on determining its safety margin to realize self-prevention of faults. When a fault appears in a grid, it will identify and isolate the fault automatically, and then adopt recovery strategies based on power flow change and the safety margin to restore the grid. Reference [3] defined a system state function according to a distribution network's voltage, current, active power, reactive power, frequency. Thereby, five different system statuses, i.e. emergency status, restore status, exception status, alert status and security status, are defined. Then, load transfer capability analysis is implemented based on $\mathrm{N}-1$ contingency analysis. The hidden risks of urban distribution networks are eliminated through on-line monitoring, checking, adjusting reactive power compensation devices or switching transmission lines. At last, the system would move into security status gradually. Reference [4] proposed a "2-3-6" framework design for self-healing grid, along with the related problems and required new technologies of self-healing control. References [3-4] could give us the idea and further research directions for the high-voltage power grid self- 
healing issue.

Current literatures on self-healing grid are usually discussing the required technology and implementation framework, paying little attention to implementing the high-voltage power grid selfhealing [5-7]. This paper will discuss the detailed realization process of high-voltage power grid self-healing. First, the concept of power grid self-healing and its research status are introduced. Accordingly, taking a specific high-voltage power grid as an example, the process of fault identification, visualization, locating, and isolation of power grid self-healing are discussed. Finally, the approach of making self-healing control together with the security and stability checking in dispatch centers are presented.

\section{Concept of Self-Healing}

Self-healing is the ability of a network to prevent a fault on it by itself and then recover from it. Self-healing control utilized to fulfill the above two targets has two significant features [8]:

i) The prevention is the main core of self-healing control. The detection, diagnosis and elimination of hidden fault must be in time.

ii) Making the system recovered from a fault with the self-repair function to ensure it has the capability of maintaining continuous operation under that condition without shedding loads.

Self-healing grid can be divided into two levels [9]: element level and system level. Element layer consists of all the primary elements, (such as circuit breakers, transformers, FACTS devices, etc) and secondary elements (such as all kinds of protection and automatic devices) of a power grid. Element level self-healing mainly pays attention to a partial repair or replacement of a piece of equipment. System level, on the other hand, focuses on the self-isolation of a fault to make sure transmission and distribution function without any interruption. In order to guarantee normal operation of the whole system to the maximum extent, it should involve the handling of multiple elements based on system-wide information.

\section{Fault Identification}

After the construction of a smart grid, most substations can be paid less attention than ever before. When a fault appears in the grid, its control center needs to collect the fault information from the related substations and then identifying the fault point based on the expert knowledge base and determining the fault point through the visualization technology. This paper takes a $220 \mathrm{kV}$ power grid control center in East China Power Grid as an example to discuss the procedure. The control center only controls station A and station B. The connection diagram of station A is shown in Fig.1. Station A is a 4-section busbar connection, the same as Station B. The four sections of 220kV bus are named as the first sectioned bus, the second sectioned bus, the third sectioned bus, the fourth sectioned bus respectively. The four sections are connected by four beakers: the first sectioned breaker 2012, the second sectioned breaker 2021, the first coupler breaker 2011 and the second coupler breaker 2022.There are 7 incoming and outgoing lines connected to the $220 \mathrm{kV}$ buses. The power is transmitted to four $35 \mathrm{kV}$ buses through two main transformers, each of which supplies power to several terminal loads via four $35 \mathrm{kV}$ bus bars. $35 \mathrm{kV}$ bus 1 and bus 4 are sectioned by the second $35 \mathrm{kV}$ sectioned breaker 314 , and $35 \mathrm{kV}$ bus 2 and bus 3 are sectioned by the first $35 \mathrm{kV}$ sectioned breaker 332.Station A and station B are connected through line 4175 and line 4176.

How to identify fault, isolate the failure point and carry out the recovery procedures in control center will be discussed in the following. It is assumed that stability problem would not appear while this fault happening and the connection of the $220 \mathrm{kV}$ power grid is very compact. Therefore, no load power supply would be interrupted after the fault line is tripped off.

\section{Fault Occurrence}

The breakers' positions of Station A before a fault are shown in Figure 1. A black pane denotes the breaker is closed, otherwise means that the breaker is open. The loop is in operation if its breaker is 
closed. The tripped signals of all protective devices are provided in Table 1. The breakers' positions after the fault are outlined in Fig.2. The breaker of line 4175 in Station B also trips off.

Fig. 2 and Table 1 show that the fault point is between the breaker and current transformer at the Station A side of line 4181. As this point is the protection zone of both bus bar differential protection and line protection at the same time, two sets of protection of line 4181 and the $220 \mathrm{kV}$ first sectioned bus differential protection tripped. All the breakers linked to the $220 \mathrm{kV}$ first sectioned bus and the breakers at both sides of main transformer 1 tripped off. The breaker of line 4175 in Station B is tripped by remote tripping of line 4175 protection in Station A. After the loss of power on $35 \mathrm{kV}$ bus 1 and $35 \mathrm{kV}$ bus $2,35 \mathrm{kV}$ sectioned breaker 314 and 332 are closed by the automatic switching protection.

\section{Identify Faults Using Expert Knowledge Base}

The information about protection tripping and the change of breaker status of all the loops should be collected to the power grid control center. The action set is pre-established for every possible fault point under a certain connection mode of power grid. Take the fault between the breaker and current transformer of line 4181as an example, the action set is as follows: $\{2012$ in Station A, 2011 in Station A, 2010 in Station A, 311 in Station A, 312 in Station A, 4175 in Station A, 4181 in Station A, 4173 in Station A, 4175 in Station B, 332 in Station A, 314 in Station A, CSL-101A of line 4181 in Station A, LFP-902A of line 4181 in Station A, the $220 \mathrm{kV}$ first sectioned bus differential protection REB103, REL551(I) remote trip protection of line 4173 in Station A, REL551(II) remote trip protection of line 4173 in Station A, REL551(I) remote trip protection of line 4175 in Station A, REL551(II) remote trip protection of line 4175 in Station A, REL551(I) remote trip protection of line 4175 in Station B, REL551(II) remote trip protection of line 4175 in Station B, 35kV automatic switching . The action area is marked by dashed lines in Fig. 2 .

When the fault occurred, the fault information is gathered by the control center to form the action set. Then the action set will be matched with the pre-established action set of each fault point to identify the fault.

It is important to indicate that the action sets are made based on a certain mode of operation. When the operation mode changed, the action sets should be amended accordingly. In general, several action sets should be pre-established for all the possible changes of bus connection modes.

This paper only considers a single failure point. If complex faults, protection malfunctions or breaker failures are needed to be considered, the action sets can be made according to the corresponding situations.

\section{Confirmation The Failure Point}

In traditional passive two-dimensional monitoring mode, the information that exceeding operation limit or an accident has occurred is often showed by alarms and accident windows. Dispatchers monitor power grid status with the plant or station maps, geographical diagram, charts and alarm window. In the intelligent visualization mode, the intelligent visualization support platform is built to realize intelligent visual surveillance [10], analysis, early warning, decision support, fault location, accidents reminding intuitively and visual accident recovery programs [11].

Expert knowledge base can be used to identify the fault point shown in section III quickly. In order to confirm the fault point, intelligent robot can be used to inspect and return clear pictures or real-time video. For the GIS equipment, images can be retrieved from the cameras installed inside the GIS. For the fault shown in section III, from the images, cracks can be seen in the current transformer ceramic vases at the side of Station A of line 4181. After the confirmation of fault point, the personnel in the grid control center can start the automatic recovery plan. 


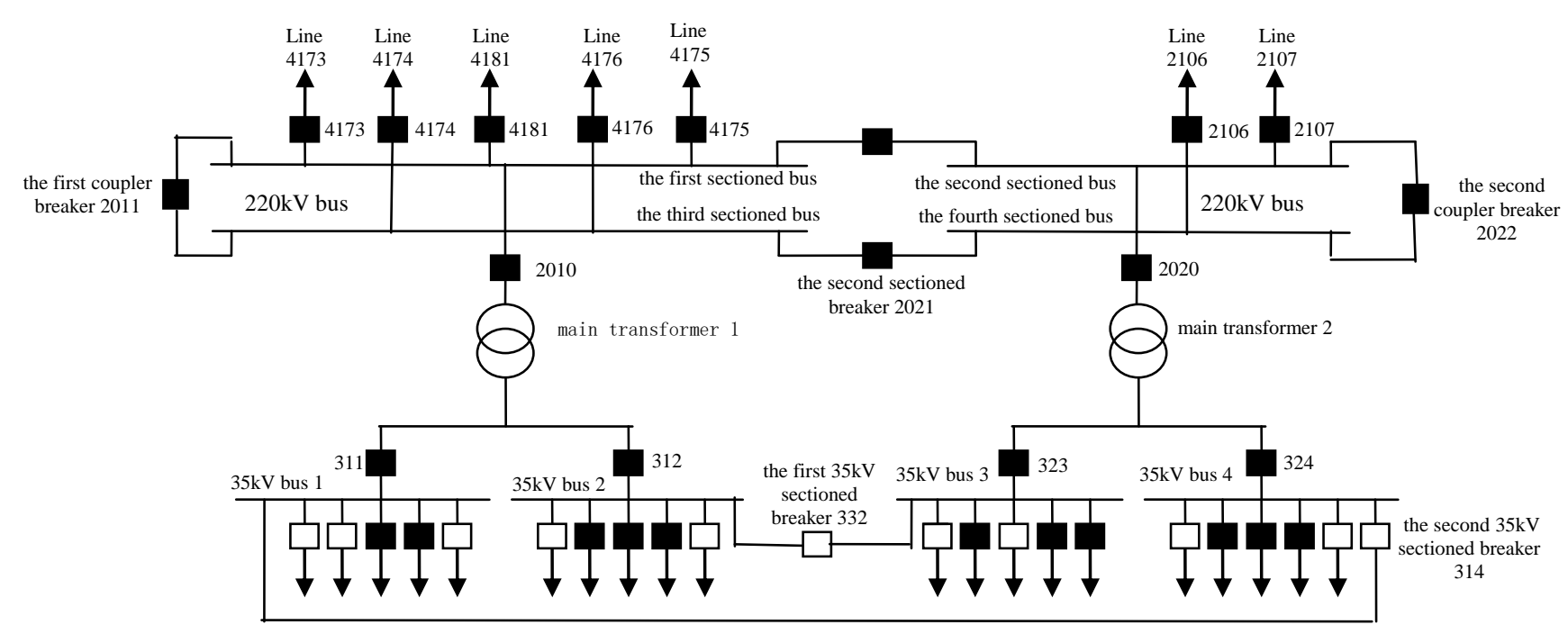

Fig. 1. The line diagram of Station A before fault

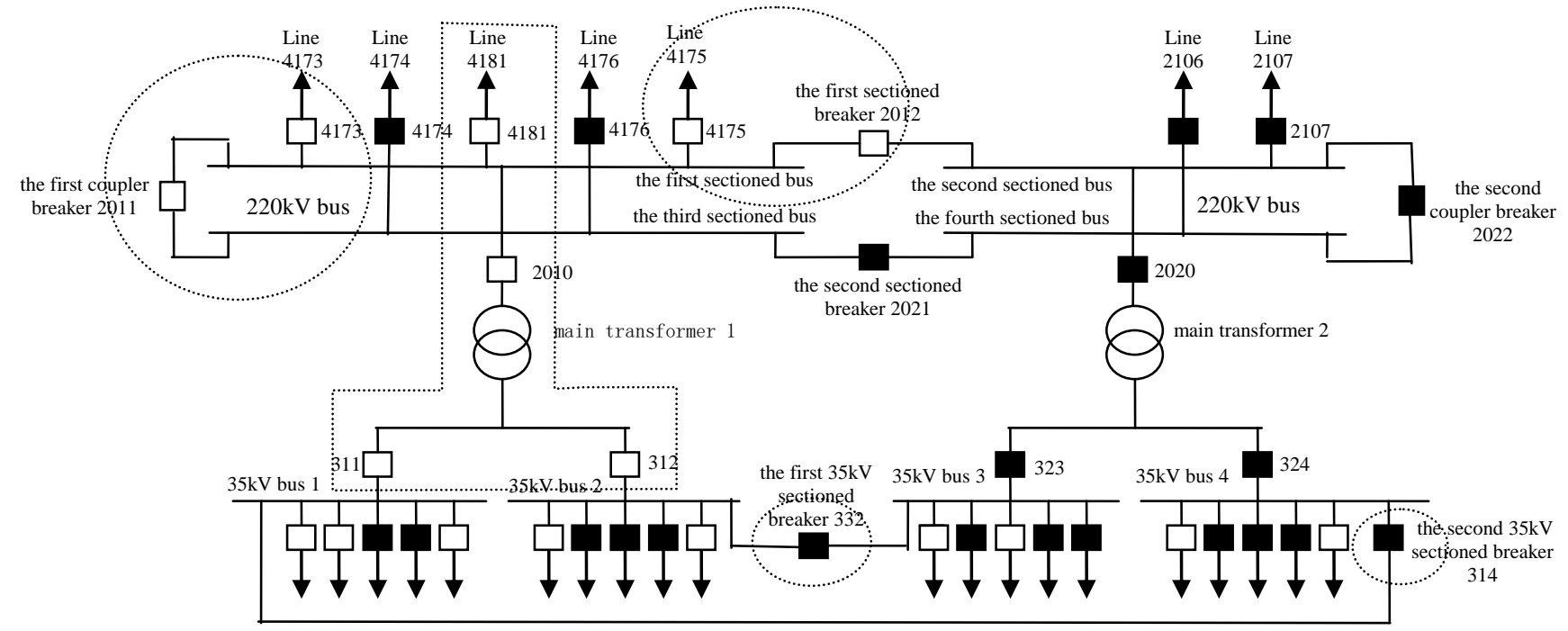

Fig. 2. The line diagram of Station A after fault 
Table 1 The trip signal of relay protection after fault

\begin{tabular}{|c|c|c|c|c|}
\hline Station & equipment & protection type & signals on the protection cubicle & the trip information of protections \\
\hline Station A & Line 4181 & CSL-101A & $\begin{array}{c}\text { The trip lights of phase } \mathrm{A}, \mathrm{B}, \mathrm{C} \text { are } \\
\text { on }\end{array}$ & $\begin{array}{l}\text { The first section of impendence, zero-sequence } \\
\text { protection tripped. The fault location result is } \\
0.07 \mathrm{~km} \text { at phase C }\end{array}$ \\
\hline Station A & Line 4181 & LFP-902A & $\begin{array}{c}\text { The trip lights of phase A,B,C are } \\
\text { on }\end{array}$ & $\begin{array}{l}\text { Distance relaying based on fault component and } \\
\text { the first section of impendence protection tripped. } \\
\text { The fault location result is } 0 \mathrm{~km} \text { at phase } \mathrm{C} \text {. }\end{array}$ \\
\hline Station A & Line 4181 & $\begin{array}{c}\text { Common } \\
\text { operation cabinet }\end{array}$ & $\begin{array}{l}\text { The second group trip lights of } \\
\text { phase } A, B, C \text { are on }\end{array}$ & \\
\hline Station A & Line 4173 & REL551(I) & the green and yellow lights are on & REL551(I) remote trip protection tripped \\
\hline Station A & Line 4173 & REL551(II) & the green and yellow lights are on & REL551(II) remote trip protection tripped \\
\hline Station A & Line 4173 & $\begin{array}{c}\text { Common } \\
\text { operation cabinet }\end{array}$ & $\begin{array}{l}\text { The first and second group trip } \\
\text { lights of phase } A, B, C \text { are on }\end{array}$ & \\
\hline Station A & Line 4175 & REL551(I) & the green and yellow lights are on & REL551(I) remote trip protection tripped \\
\hline Station A & Line 4175 & REL551(II) & the green and yellow lights are on & REL551(II) remote trip protection tripped \\
\hline Station A & Line 4175 & $\begin{array}{c}\text { Common } \\
\text { operation cabinet }\end{array}$ & $\begin{array}{l}\text { The first and second group trip } \\
\text { lights of phase A,B,C are on }\end{array}$ & \\
\hline Station A & $\begin{array}{l}220 \mathrm{kV} \text { first } \\
\text { sectioned } \\
\text { breaker }\end{array}$ & CZX-12R & $\begin{array}{c}\text { The trip lights of phase A,B,C are } \\
\text { on }\end{array}$ & \\
\hline Station A & $\begin{array}{c}220 \mathrm{kV} \text { first } \\
\text { coupler breaker }\end{array}$ & CZX-12R & $\begin{array}{c}\text { The trip lights of phase A,B,C are } \\
\text { on }\end{array}$ & \\
\hline Station A & $\begin{array}{r}35 \mathrm{kV} \\
\text { automatic } \\
\text { switching }\end{array}$ & SEL351 & $\begin{array}{l}\text { Automatic switching trip lights of } \\
\text { the first } 35 \mathrm{kV} \text { sectioned breaker and } \\
\text { the second } 35 \mathrm{kV} \text { sectioned breaker are } \\
\text { on. }\end{array}$ & \\
\hline Station B & Line 4175 & REL551(I) & the green and yellow lights are on & REL551(I) remote trip protection tripped \\
\hline Station B & Line 4175 & REL551(II) & the green and yellow lights are on & REL551(II) remote trip protection tripped \\
\hline Station B & Line 4175 & $\begin{array}{c}\text { Common } \\
\text { operation cabinet }\end{array}$ & $\begin{array}{l}\text { The first and second group trip } \\
\text { lights of phase } A, B, C \text { are on }\end{array}$ & \\
\hline
\end{tabular}




\section{The Isolation of A Failure Point}

After the location of the failure is identified, the automatic recovery plan must complete the isolation of the failure in the first place. So that, the healthy part of the grid can be switched into operation again, and the fault part can be repaired at the same time. The separation process is: turning line 4181 at station B into cold standby, and then, changing the line 4181 and its breaker state at station A into maintenance.

\section{Auto-recovery of a Power Grid}

After the isolation of the fault, the first section of $220 \mathrm{kV}$ bus in station A will be turned into cold standby state. Then, the $220 \mathrm{kV}$ first sectioned breaker 2012 will be used to charge the first section of $220 \mathrm{kV}$ bus. After the success of charging, all the loops except line 4181 in this section can be restored in turn. For each line, it should be charged, loop closed in turn in accordance with the rules provided by dispatch centre. These operations should work with other grid control center. The high voltage side breaker 2010 in station A is closed to energize the main transformer 1 . After the charge is successful, close the low voltage side breakers 311,312 of main transformer 1 , open the first $35 \mathrm{kV}$ sectioned breaker 332 and the second $35 \mathrm{kV}$ sectioned breaker 314 . By then, the connection mode returns to normal. This greatly reduces the recovery time of the power accident.

As the line 4181 is out of service for an overhaul, the operation mode has been changed. There may be some lines or equipments need to modify the set value. The auto-recovery plan will switch the set value area on-line automatically before closing breakers to recover power supply.

\section{Prevention and Tuning Control}

$\mathrm{N}-1$ principle of power system static security analysis method is applied for failure prediction in present operation mode. Load transfer capacity is investigated based on the $\mathrm{N}-1$ state to prevent the self-protection measures of power grid are inadequate when other failure occurs during this period.

The following actions embody the concept of self-prevention. In the dispatch center, coordinated control and defense can be achieved through online intelligence-assisted decision-making and prevention control system. Multiple faults, faults in different plants and stations at the same time, power failure one after another can also be handled by emergency control. When the control measures of automatic device in the existing power grid are insufficient, the additional control of grid security and stability can be achieved from the perspective of the whole grid to make up for the insufficiency of regional and local emergency control measures.

Reference [8] proposed an algorithm that higher-level grid control center track changes and make out external network equivalent model automatically for the lower-level control center. The lowerlevel control center can do self-healing based on the equivalent model provided by higher-level grid control center. In reference [3], the state of distribution power grid is defined as the security status, alert status, and exception status, restore status and emergency status. Self-healing control program is always doing non-stop test to judge whether power grid is in security status. That is, to determine whether the abnormal situation is under control, whether there are facilities abnormal, overload, voltage instability and so on. Tuning control should be done when power grid deviates from the security state. So the ideas and methods can be learnt from reference [3] to determine the state of high-voltage power grid, but the stability problem of high-voltage power grid is more complex and other auxiliary criterion is required.

After fault occurs, there maybe a larger load transfer in adjacent lines. Overload will happen in a portion of transmission lines. If the fault line can't be restored immediately, self-healing control should make some adjustment to the distribution of power flow. The power flow limitation can be 
controlled by reducing or increasing the output power of some relevant generators. The grid structure control should be done when in the absence of load transfer capacity. High-voltage power grid can be turned into safe state through on-line monitoring, checking, adjusting reactive power compensation equipment, switching lines, putting remote power into operation, load-shedding, splitting, etc.

\section{Conclusion}

Compared to traditional manual dispatching and manual recovery approach, the advantages of selfhealing control are in this rapidness and effectiveness. It can make processing strategies more quickly through the comprehensive collection of system status information. This would save significant time in decision making in order to avoid cascade tripping caused by large load transfers.

The concept of self-healing and its research status is introduced. The methods to prevent the system entering emergency status or exception status and to implement tuning control are also presented. Taking an actual failure appearing in a $220 \mathrm{kV}$ power grid as an example, the self-healing process of a high-voltage power grid is introduced. It consists of collecting information by a power grid control center, determining the point of failure according to the trip information, and affirming the fault point by visualization technology. Accordingly, the recovery programs could be started. The example demonstrates the validation of this self-healing scheme.

\section{References}

[1] S. Su, K. K. Li, W. L. Chan, X. Zeng, and X. Duan, "Agent-based self-healing protection system," Power Delivery, IEEE Transactions on, vol. 21, pp. 610-618, 2006.

[2] Y. Haibo, V. Vittal, and Y. Zhong, "Self-healing in power systems: an approach using islanding and rate of frequency decline-based load shedding," Power Systems, IEEE Transactions on, vol. 18, pp. 174-181, 2003.

[3] G. Xin-xin, J. Ning, and J. Kan, "Practice and Prospects of Self-healing Control of Intelligent Distribution Grid," Electric Power Construction, vol. 30, pp. 4-6, 2009.

[4] G. Zhizhong, "Schemes of self-healing control frame of power grid," Automation of Electric Power Systems, vol. 29, pp. 85-91, 2005.

[5] M. Amin, "Toward self-healing energy infrastructure systems," Computer Applications in Power, IEEE, vol. 14, pp. 20-28, 2001.

[6] S. Massoud Amin and B. F. Wollenberg, "Toward a smart grid: power delivery for the 21st century," Power and Energy Magazine, IEEE, vol. 3, pp. 34-41, 2005.

[7] K. Moslehi, A. B. R. Kumar, D. Shurtleff, M. Laufenberg, A. Bose, and P. Hirsch, "Framework for a self-healing power grid," in Power Engineering Society General Meeting, 2005. IEEE, 2005, p. 3027 Vol. 3.

[8] Z. Boming, S. Hongbin, W. Wenchuan, and G. Qinglai, "Future Development of Control Center Technologies for Smart Grid," Automation of Electric Power Systems, vol. 33, pp. 21-28, 2009.

[9] W. Qiulan, "Theory Study for Self-healing of Large Power Grid," Automation of Electric Power Systems, vol. 33, pp. 29-32, 2009.

[10] C. Jia, S. Hongbin, and T. Lei, "Three-dimensional Visualization Technique for Power System Control Centers and Its Real-time Applications," Automation of Electric Power Systems, vol. 32, pp. 20-24, 2008. 
[11] Y. Sheng, Y. Jian-guo, Y. Zhi-hong, and G. Zong-he, "Study on Key Technologies in Smart Grid Dispatching," Electric Power Construction, vol. 30, pp. 1-4, 2009. 